\title{
A Systematic Review of Smart Clothing in Sports: possible Applications to Extreme Sports
}

\author{
S. Scataglini ${ }^{1}$, A. P. Moorhead ${ }^{2}$, F. Feletti ${ }^{3,4}$ \\ 1 Department of Product Development, Faculty of Design Science, University of Antwerp, Belgium \\ 2 Department of Mechanical Engineering, Politecnico di Milano University, Milan, Italy \\ 3 Department of Diagnostic Imaging, Ausl Romagna, S. Maria delle Croci Hospital, Ravenna, Italy \\ ${ }^{4}$ Department of Electronics Information and Bioengineering, Politecnico di Milano University, Milan, Italy
}

\author{
CORRESPONDING AUTHOR: \\ Sofia Scataglini \\ S.MU-PO.3.09 \\ 2000 Antwerpen, Belgium \\ E-mail: sofia.scataglini@uantwerpen.be
}

DOI:

10.32098/mltj.02.2020.19

LEVEL OF EVIDENCE: $3 a$

\begin{abstract}
SUMMARY
Background. Traditional monitoring of athletes during sports has long been hampered by bulky, complicated and tethered systems. In the past decade, this has changed due to the miniaturization of sensors and improvement of systems to store and transmit data. These systems have been integrated into textiles to create 'smart clothing' which has been so ubiquitous that a review of the recent literature is crucial for understanding its full potential and potential use in extreme sports.

Methods. An electronic data base search was performed from 2003 to April 2019 for full length articles including "Smart" AND "Clothing" OR "Clothing" AND "Sport(s)" written in English with human subjects. Articles were evaluated according to the Newcastle-Ottawa Scale.

Results. Twenty-four studies resulted in 18 systems comprised of 22 types of clothing with various capabilities, including: monitoring heart rate, electromyography, respiratory rate, steps, GPS, energy expenditure, posture, body temperature and identifying the activity.

Conclusions. Many types of smart clothing from socks and gloves, to pants, shirts and bras are increasingly utilized to monitor sports activity worldwide and gather previously unavailable, yet highly valuable data. This provides a unique opportunity to study athletes during training and competition, potentially providing more effective training and better safety protocols.
\end{abstract}

KEY WORDS

Smart, clothing, sensorized, textiles, sport, extreme.

\section{INTRODUCTION}

Until recently, monitoring athletes during competition or training has been difficult, if not impossible, due to the systems used. Traditional methods for studying athletes were once restricted by the need of the systems to either be connected to power, or for the sensors to be directly tethered to the processors, which kept many studies limited to laboratories rather than performing experiments in the field of play. Additionally, many of these systems were bulky and restrictive, which inhibited athletes from performing as they normally would. In recent decades however, advancements in textiles and sensor technology have led to the creation of sensorized garments as an alternative to uncomfortable, tethered systems. Innovations in sportswear have resulted in new, sport-specific textiles compositions for improved aerodynamics, stimulus-responsive polymers and aerogels, and specialized coatings for thermal and perspiration management (Rossi et al, 2018). Simultaneously, sensors have been reduced in size and integrated into these specialized textiles to make "smart clothing." Smart clothing allows athletes to perform their sports unencumbered while physiological (heart rate, respiration), performance (posture, movement), and environmental (temperature, humidity) data are acquired in real-time (Lam Po Tang et al., 2015). This is particularly advantageous in extreme sports where athletes commonly make rapid decisions and acrobatic movements in adverse environments and any interference could be potentially dangerous.

Smart clothing systems have increasingly levels of complexity and capability which is commonly classified in three different categories: passive, active and ultra-smart textiles. Passive smart garments can only perceive the data 
from the human body or the environment such as step count, calories or heart rate. Active smart fabrics involve both sensors and actuators like stretch sensors are elastic bands that include soft capacitors, which when stretched, provide reliable data about human body motion (Koncar V, 2019). Finally, ultra-smart garments can sense, and by means of integrated microcomputers, intelligently elaborate diverse data types in order to make predictions and respond to external requirements. For example, spacesuits are able to thermoregulate the human body, depending on the environmental temperature (Pailes-Friedman, 2016). Some of these systems are made even more effective by also incorporating radio-frequency identification (RFID) chips in the textile constructions to both sense and transmit data wirelessly transmitted, known as telemedicine (Joyce 2019; Gaddis, 2014; Syduzzaman, 2015, Di Rienzo et al., 2010). This offers functionality in a diverse range of previously unavailable environments and also means that athletes do not need to sacrifice training time to perform experiments.

Due to the capabilities of smart clothing, many applications have been proposed including training, competition, recovery and even safety. Lam Po Tang (2015) states that real-time biofeedback can be used to provide input on improving movement and reducing human error. By gathering data from previous bouts of exercise, the systems could suggest safer movement patterns or with real-time built in alerts, smart clothing could even help to reduce injury during participation. Smart clothing is a necessary and welcomed improvement to activity monitoring since these once challenging factors resulted in extreme sports being previously neglected in research. As smart clothing becomes increasingly ubiquitous, a review of the current literature is essential to better understand the variety of materials, sensors and combinations currently available as well as their most beneficial uses. The aim of this review is to summarize the most recent research of smart clothing and identify its potential applications so that athletes, trainers, researchers, and practitioners have a better understanding of its functional application in extreme sports.

\section{METHODS}

This systematic review was conducted according to the preferred reporting items for systematic reviews and meta-analyses (PRISMA) guidelines (Harris, 2014).

\section{Search strategy}

A comprehensive electronic literature search was conducted in April 2019 on the following electronic databases (2003 or more recent): Web of Science, Science Direct, PubMed, IEEE and Scopus database. Custom queries using keywords and Boolean logic with AND/ OR were entered in the search engines with the following terms: ("Smart" AND "clothing") OR ("clothing" AND "sports" OR "sport"). The search included only full length original articles on human subjects and written in English.

\section{Inclusion Criteria}

The adopted inclusion and exclusion criteria were defined according to the (P; Patients, I; Intervention, C; Comparison, O; Outcomes) PICO components reported in table I. All the 24 of the included studies were evaluated according to the Newcastle-Ottawa Scale (NOS) by an engineer specialized in the field of smart clothing.

Table I. Eligibility criteria.

\begin{tabular}{|c|c|c|}
\hline Selection Criteria & Inclusion criteria & Exclusion Criteria \\
\hline Population & Humans & Not humans \\
\hline Intervention & $\begin{array}{l}\text { Smart clothing } \\
\text { for monitoring sport }\end{array}$ & Wearable Device \\
\hline Control & $\mathrm{N} / \mathrm{A}$ & $\mathrm{N} / \mathrm{A}$ \\
\hline Outcome & N/A & N/A \\
\hline Design & $\begin{array}{l}\text { Meta-analysis, RCT, cohort } \\
\text { studies, case control studies }\end{array}$ & $\mathrm{N} / \mathrm{A}$ \\
\hline Language & English & Not written in English \\
\hline Other & Smart Textile for monitoring sport & $\begin{array}{l}\text { Non-textile smart materials(1) not sport related } \\
\text { papers (2) }\end{array}$ \\
\hline
\end{tabular}




\section{RESULTS}

\section{Literature search results}

A total of 837 records were identified after removing 58 duplicates. Title and abstract screening eliminated 786 papers, resulting in 51 eligible papers. Inclusion criteria then led to the exclusion of 27 papers resulting in 24 documents. The primary reasons for exclusion were the lack of compliance with the eligibility criteria (Tab.1). The selection process is represented by the flowchart in figure $\mathbf{1}$.

\section{DISCUSSION}

Study design, study object, general population, methods and results assessed according to NOS are reported in table II. After the first publication in 2003, there was an increase of pertinent publications over time. There were five from 2004-
2008, seven from 2009-2013, and 11 from 2014-2018. Most of the studies where from Europe $(72 \% ; n=17)$, followed by Asia $(12 \% ; n=3)$, America $(8 \% ; n=2)$ and Oceania $(8 \%$; $\mathrm{n}=2)$. The countries with the most publications were: UK $(23 \% ; n=6)$, Italy $(16 \% ; n=4)$ and Finland $(12 \% ; n=3)$. The majority of these studies were overviews $(29 \%$; $n=7)$ of textile, followed by overviews of requirement for designing smart clothing, overviews of the current status and future changes, products or prototypes, and data transfer. In total, we examined the data relative to 18 intelligent systems (See table III), some including more parts and accounting for a total of 22 types of clothing, including 13 shirts or vests, three pants, two socks, two bras and two gloves. As reported in table 3, twelve of the devices were able to capture the heart rate, three electromyography, and five the respiratory rate. Two systems incorporate GPS, three step counting, and five measure the energy expenditure. Three systems

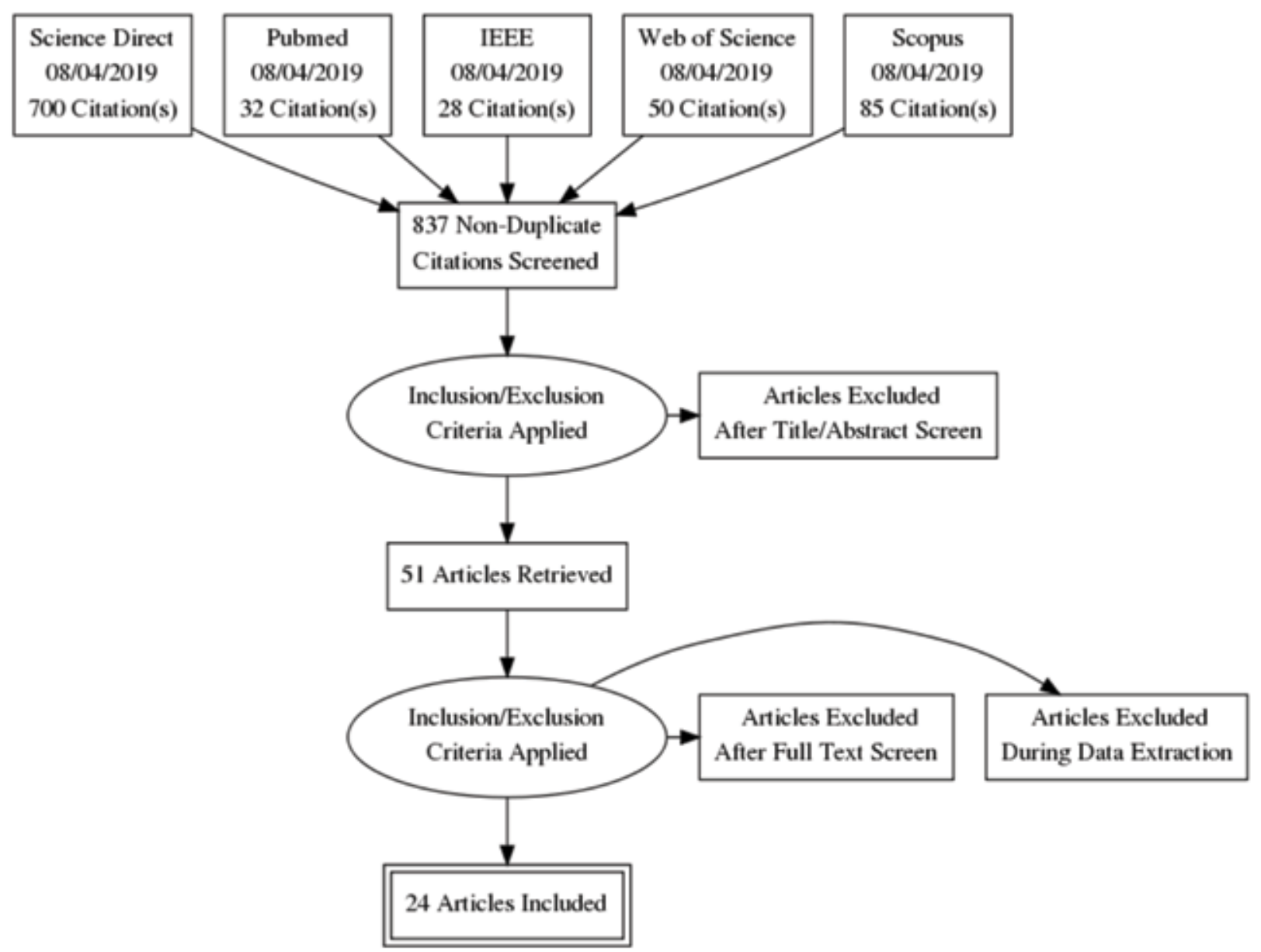

Figure 1. Flowchart of the review process. 
Table II. NOS.

\begin{tabular}{llll}
\hline Studies & Selection & Comparability & Stars \\
\hline Andreoni, Standoli, Perego, 2016 & $*$ & $*$ & 2 \\
\hline Axisa, Dittmar, Delhomme, 2003 & $* *$ & $*$ & 3 \\
\hline Balmain et al., 2018 & $* *$ & $* *$ & 4 \\
\hline Bryson, 2009 & $*$ & $*$ & 2 \\
\hline Chan et al., 2012 & $* *$ & $* *$ & 4 \\
\hline Chittenden, 2017 & $* *$ & $*$ & 3 \\
\hline Cho and Lee, 2015 & $* * * * *$ & 5 \\
\hline Di Renzo et al., 2010 & $* * * *$ & $* *$ & 4 \\
\hline Dabby et al., 2017 & $* *$ & $*$ & 3 \\
\hline Ghahremani Honarvar, M., \& Latif, M., 2016 & $*$ & $*$ & 3 \\
\hline Helmer, 2008 & $* *$ & $* *$ & 3 \\
\hline Lam Po Tang, 2015 & $* *$ & $*$ & 4 \\
\hline Manshahia, 2016 & $*$ & $* *$ & 2 \\
\hline Mečnika et al., 2014 & $*$ & $*$ & 3 \\
\hline Meinander, 2005 & $*$ & $* *$ & 2 \\
\hline McCann, 2009 & $*$ & $*$ & 2 \\
\hline Mondal, 2008 & $*$ & $*$ & 2 \\
\hline Perego, Moltani, Andreoni, 2012 & $* *$ & $*$ & 3 \\
\hline Rantanen, Marko, 2005 & $* * *$ & $*$ & 3 \\
\hline Rossi, 2018 & $*$ & $* *$ & 2 \\
\hline Tyler, 2013 & $*$ & $*$ & 3 \\
\hline Uotila, M., Mattila, H., \& Hänninen, O., 2006 & $* *$ & $*$ & 2 \\
\hline Van Langenhove, L., 2013 & $* * *$ & 3 \\
\hline Woods, 2008 & $*$ & 3 \\
\hline
\end{tabular}

Table III. Smart clothing products in sports.

\begin{tabular}{|c|c|c|c|c|c|c|c|c|c|c|c|c|c|c|c|}
\hline Reference & Smart Product & Shirt/Vest & Pants & Socks & Bra & Glove & $\mathrm{HR}$ & EMG & Resp & Steps & GPS & Cal. & Posture & Activity & Temp. \\
\hline Di Rienzo et al., 2010 & MagIC & $\mathrm{x}$ & & & & & $x$ & & $x$ & & & & & & \\
\hline Chan et al., 2010 & Moticon SkiGo & & & & & & & & & & & & $x$ & & \\
\hline Balmain et al., 2018 & Smart Vest & $\mathrm{x}$ & & & & & $\mathrm{x}$ & & & & & & & & $\mathrm{x}$ \\
\hline Tyler et al., 2013 & Smart Socks & & & $\mathrm{x}$ & & & & & & $\mathrm{x}$ & & & & & \\
\hline Alisa et at., 2003 & NuMetrex & $\mathrm{x}$ & & & $\mathrm{x}$ & & $\mathrm{x}$ & & & & & $x$ & & & \\
\hline Rossi, 2018 & MARSIAN & $\mathrm{x}$ & & & & $x$ & & & & & & & & & $\mathrm{x}$ \\
\hline Rossi, 2018 & VivoMetrics & $\mathrm{x}$ & & & & & $x$ & & & & $\mathrm{x}$ & & $x$ & $x$ & $x$ \\
\hline Lam Po Tang, 2015 & Oxstren & & & & & $x$ & $\mathrm{x}$ & & $x$ & & & $\mathrm{x}$ & & $x$ & $\mathrm{x}$ \\
\hline Lam Po Tang, 2015 & SensVest & $x$ & & & & & $x$ & & & & & & & $x$ & \\
\hline Lam Po Tang, 2015 & Athos & $x$ & $x$ & & & & $\mathrm{x}$ & $\mathrm{x}$ & $\mathrm{x}$ & & & & & & \\
\hline Lam Po Tang, 2015 & Sensoria & & & $\mathrm{x}$ & & & $x$ & & & $x$ & & $x$ & & $x$ & \\
\hline Lam Po Tang, 2015 & Hexoskin & $x$ & & & & & & & $x$ & $x$ & & $x$ & & $x$ & \\
\hline Lam Po Tang, 2015 & Mbody & & $x$ & & & & & $x$ & & & & & $\mathrm{x}$ & & \\
\hline Lam Po Tang, 2015 & OM & $\mathrm{x}$ & & & & & $\mathrm{x}$ & & $x$ & & & & & $x$ & \\
\hline Lam Po Tang, 2015 & Smartlife & $x$ & & & $x$ & & $\mathrm{x}$ & & & & $x$ & $\mathrm{x}$ & & & \\
\hline Lam Po Tang, 2015 & AiQ, BioMan & $x$ & & & & & $\mathrm{x}$ & $\mathrm{x}$ & & & & & & & \\
\hline Chittenden, 2017 & Heddok & $\mathrm{x}$ & $\mathrm{x}$ & & & & & & & & & & & $\mathrm{x}$ & \\
\hline Perego, et al., 2012 & Mart T shirt & $\mathrm{x}$ & & & & & $\mathrm{x}$ & & & & & & & & \\
\hline & TOTAL & 13 & 3 & 2 & 2 & 2 & 12 & 3 & 5 & 3 & 2 & 5 & 3 & 7 & 4 \\
\hline
\end{tabular}


measure the posture, seven identify the activity and four measure the body temperature.

\section{Human System Interaction and Human-Centred Design in Smart Clothing in Sport}

Smart clothing or "intelligent textile" represents a new class of wearable textile design systems with interactive technologies. Smart garments used in extreme sports should be specifically designed and built for the sport or missions they want to monitor. For example, some parts of the clothing, such as the electronic modules, can interfere with the sport equipment, including backpacks or specific harnesses; in these cases, special pockets or housings must be added (Di Rienzo, 2010). Special consideration must be given to the materials. Since many of these sports are practiced in particular climatic conditions and sometimes directly in contact with water, it is essential that the garment could contribute to thermal comfort of the subject. As a matter of fact, wet garments can be dangerous at low temperatures, while in warm humid climate conditions perspiration is crucial. Therefore, in extreme environmental conditions, synthetic materials such as neoprene or polypropylene may be preferred to cotton
(Di Rienzo, 2010). Finally, the design must be optimized in order to ensure appropriate freedom of movement, and specific inserts of elastic fabric can be added in those areas that require maximum adherence to the body or freedom of movement. The human system interaction can be active (sensoric, adaptive, self-healing) or passive (e.g. barrier against wind, rain, or cold). Rantanen and Hännikäinen (2005) suggested a conceptual model that describes the architecture and the human system interaction of a smart clothing, figure 2 .

According to this model, the inner clothing maintains the interface between the human and the textile. This layer can be connected with an outer layer with an insulation purpose. According to Andreoni et al. (2016) both layers can be served by user interfaces, such as buttons, fixing support and switches, or connectors providing input to the garments. Communication affects the smart clothing internally (data transfer between the separate components), externally (data transfer between smart clothes and external network), and spatially (data exchanges place between internal and external). Bryson (2009) addressed the relationship between design and the anatomical features, physiology and psychology, thus highlighting the role of human-centered design (figure 3 ).



Information networks

Figure 2. Concept model of smart clothing (Rantanen and Hännikäinen, 2005). 


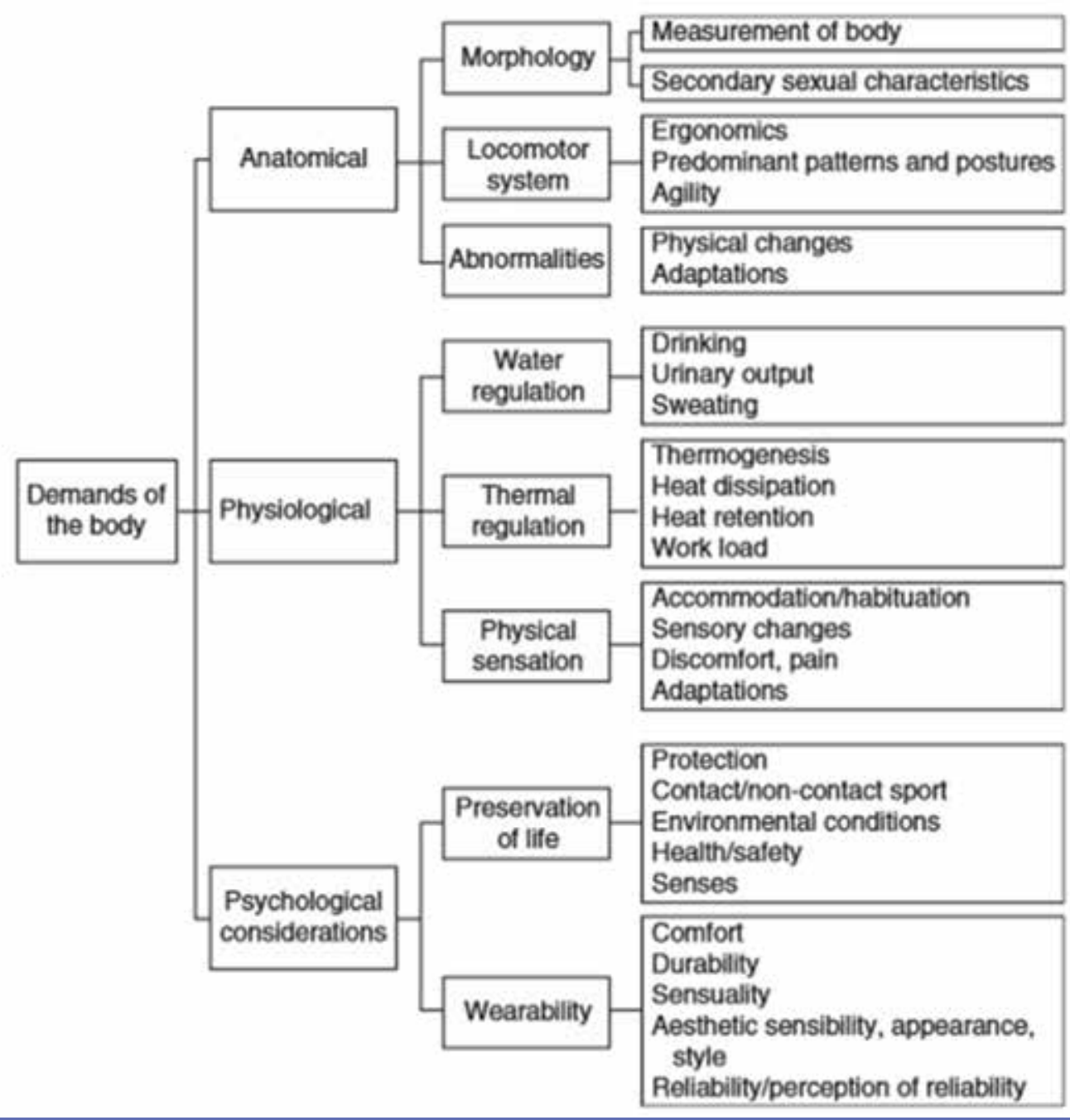

Figure 3. Schematic design of smart clothing design based on the demands of the body according to Bryson (2009).

McCann 2009, defined the garment design process for smart clothing using a different process. This process starts with the identification of the user and the user's needs by comparing the commercial realities. This step is followed by the $2 \mathrm{D}$ development of the garment together with the textile selection. The following step involves the initial 3D development with the measurement/ body sizing both with traditional and digital methods. In functional garment for sport, the joining technology uses innovative systems such as seamless, whole garment and knit \& wear. Moreover, garment bonding, and stitch-free laser welding are used where it is necessary to develop high performance sportswear. Alongside the smart textile technology and the design of technology interface are developed.

\section{Smart Materials}

Smart materials in sportswear include fibers, yarn, fabric, coatings, finishes and membranes.

As explained by Ghahremani, Honarvar, and Latifi (2016), conductive fibers or Electronic Textile (E-textile) are fibers that conduct electricity through the smart clothing. They consist of natural (ferrous alloys, nickel, stainless steel, titanium, aluminum, copper) or threaded conductive fibers (conductive metal or carbon powders). As depicted in figure 4 , conductive fibers can be merged with insulating fiber to create different structures.

When more than one fiber is interlocked, it is called yarn. The yarn can be made by conductive polymers or metallic fibers (natural, synthetic or created by wrapping). In turn, 


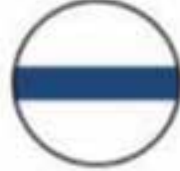

Sandwichtype fiber

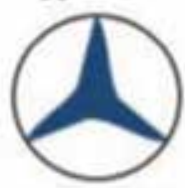

Trilobal core fiber

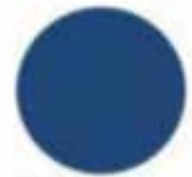

Wholly conductive fiber

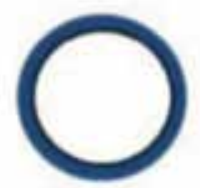

Shell conductive fiber

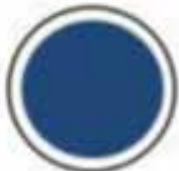

Core conductive fiber

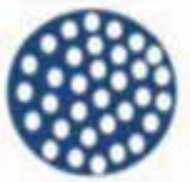

Coated yarns

\section{Conductive material}

Insulating material

Figure 4. Different structures combining conductive (blue) and insulative (white) fibers to produce conductive textiles (Ghahremani, Honarvar, and Latifi, 2016).

the fibers could be used for embroidery, knitting and weaving, creating a garment. Conductive inks are inks with a metal precursor such as carbon, copper, silver, nickel and gold. Optical fibers can be integrated in the textile in order to transmit data signals, light or detect information related to stress and strain inside the fabric. Smart coatings such as phase change materials, moisture-responsive shape memory polymer, and conductive coatings are materials that can sense and respond to external stimuli and have recently been used in the production of sportswear. Smart coating with nano-particles can enhance the textiles with properties such as anti-bacterial, water-repellence, UV-protection and self-cleaning, while still maintaining breath-ability and tactile properties of the textile. Smart coatings for protection are smart membrane. Fluoroethylene membrane (PFTE) and Gore-Tex are created to protect the fabrics from water, while polyurethane membrane, like Porelle Dry, Dorminaz NX are used for waterproof breathable fabric.

\section{Smart Coatings for performance enhancement}

Smart coatings can be used to reduce drag in sports such as cycling, sprinting, and swimming. For example, biometric Swimsuit Fastskin ${ }^{\circledR}$ is a fabric inspired by the skin of a shark which has dimples on its surface which greatly reduce the drag through water.

\section{Smart Coatings to enhance comfort}

Phase change materials (PCM) are materials that responds to any external stimuli passing from one state to another, like solid to liquid, or vice versa. PCM microcapsule can change state from solid to liquid with temperature donating a cooling effect (when temperature raised to $29^{\circ} \mathrm{C}$, they became liquid) or heating effect (when the temperature goes below $27^{\circ} \mathrm{C}$, they solidify). PCM acts also as a barrier for the human body by creating thermoregulatory effects around the body by keeping the surrounding temperature constant either through heat emission or absorption. An example is the Outlast ${ }^{\circledR}$ technology originally developed by NASA for the temperature variation in space. The PCM microcapsule can be incorporated into fabrics and fibers giving the garment the capacity to absorb and release heat.

\section{Shape Memory materials}

In shape memory materials (SPM), moisture acts as external stimuli. An example is Nike sphere react t-shirt made by bilateral structure. An outer layer with U-shape (non-swelling and non-hygroscopic) and an inner layer (hygroscopic in nature). In this case, during an activity, the moisture acts as an external stimuli provoking the $\mathrm{U}$ shaped windows to curl back, while the opening increase the air permeability and cool down the body, allowing faster drying.

\section{Physiological and Performance Monitoring}

Bio signals are usually collected on the skin surface through sensors. The basic signals and the main parameters that can be measured by a smart textile are related to cardiac function such as hear activity (ECG), muscle activation (EMG), and respiratory rate. These signals are measured by electrodes which can be embedded into the cloth becoming textrodes. These sensors have the advantage of not requiring electro-conductive gel on the electrodes, also making them more ecologically friendly. The skin moisture and perspiration acts as electrolyte layer between textile and skin. This can be seen as stainless steel yarns that are used to embroider electrodes. These electrodes present high conductivity, but low elasticity and weight. The silver-coated polymer foams have the advantage of being antibacterial, but as metal-coated sputtered fabric, present poor washability. Signal strength is affected by the choice of the material and its integration into the cloth. In fact, ECG sensors, in particular textrodes, must be placed in an optimal position into the garment to prevent movement related artefacts. Dabby et al. (2017) described the process to building the garment with ECG textrodes embedded. While, Cho and Lee (2015) studied 56 electrode positions determining a smart vest grid with $6 \mathrm{~cm}$ intervals in 
front and back of the bodies. Ten subjects were monitored in the 56 different positions. A participant stayed still in upright posture wearing the smart vest. Fifty-six task sets of the experimental motion were repeated three times with ten second interval (Cho and Lee 2015). The optimal position (determined as the "maximal impulse") was shown to be in the $5 \mathrm{~d}$ and the $2 \mathrm{~d}$ positions, which correspond to the inferior, lateral side of the muscle pectoralis major. Together with cardiac data, smart clothing in sport can be used for monitoring breathing data, muscle activity, temperature, humidity or sweat data. In particular, textile structures that contains electro-conductive material can be used as strain gage for measuring respiration rate. Stainless yarns, for example, can be knit into a Lycra to provide stretch constituting a textile sensor for measuring respiration. Or, conductive polymer polypyrrole can be associated with Lycra constituting a chest-band integrated in a shirt for measuring the breathing rate (Lam Po Tang 2015). As an alternative, De Rossi (2018) coated yarns and fabrics with carbon loaded rubber to create a piezoresistive fabric strips positioned at the thorax and abdominal level. Andreoni et al., 2016 presented a smart shirt for monitoring respiration through textile strain gauges at thorax and at abdominal level. Di Renzo et al.2010 and Perego et al. 2015 presented one single lead ECG that is obtained by two knitted electrodes integrated in a vest and shirt at thorax level. In particular, the wearable system developed by Perego et al (2015) was used to capture the ECG signal along with three axial acceleration during a skyrunning race. Di Renzo et al.2010, presented the MagIc that below the textrodes for the ECG integrates piezoresistive plethysmograph that detect change in the thorax.

\section{Textile sensors for kinematic monitoring in Sport}

Kinematic analysis can be done through the use of body-worn accelerometers attached to the cloth by two snaps attached on the chest of a smart t-shirt to monitor the activity, balance and gait. Multiple accelerometers or inertial systems can be integrated in a suit constituting a motion capture system. Strain sensors integrated into a cloth can provide the characteristic of the movement or posture. A GPS or antenna can provide information such as speed and location.

\section{Smart clothing products}

Table 3 is a summary of the smart clothing products in sports which were found during this review, as well as their functionality. Athos smart garments (pants) are smart training tools used to optimize fitness level by monitoring the maximum voluntary isometric contraction (MVIC), rather than the typical neural EMG. Myotec is another smart product for measuring muscle activity that can be used for training. Also related to training, Sensoria launched a line of Smart Socks, Bra and Shirt which are connected via an app for virtual coaching during running and walking. Sensoria smart socks monitor cadence, pace, distance, foot loading and foot contacts. HR monitoring is possible using the bra or the shirt. By integrating the garments with the socks, the acquired information is used in a virtual coaching platform. HR monitoring is also possible by using the smart apparel BioMan+ (shirt, bra, vest) from AIQ or OMsignal (bra, shirt). Along with these options is a slightly different garment. Smart glove by Oxstrean can be also used for monitoring HR, respiration and hydration level during exercise, but the most complete smart garment that appears in this review is Astroskin from Hexoskin. This smart vest, born from the Canadian Space Agency with the aim to monitoring astronaut's vital signs, is now also available on the market. The Astroskin shirt measures blood pressure, pulse oximetry, 3-lead ECG, respiration, skin temperature, and activity sensors for 48 hours.

\section{Possible applications of smart clothing in extreme sports}

The use of smart clothing in extreme sports has, so far, been very limited. However, in extreme sports, these systems may be particularly useful, mainly because they allow monitoring the performance as well as physiological data in a non-intrusive way. Pressure sensors integrated in apparel can be adopted for measuring muscle activity, while strain sensors can be used for estimating muscle fatigue (EMG). These data are important not only for improving an athlete's performance, but also the quality of life by checking health status and preventing illnesses and injuries, including cardiovascular events (Di Rienzo, 2010). For example, the MagIC system was used to monitor physiological effects of altitude in ten climbers during their stay at 6000 and 6800 m (Everest South Advanced Camps 1 and 2). (Di Rienzo, 2010). Finally, smart clothing is an ideal solution for research in this field. They have been used for identifying possible countermeasures to altitude sickness (Di Rienzo, 2010). Smart clothing offers an ecological approach for monitoring physiological data monitoring of the performance of the athletes acting as safety mechanism in acting sport informing his team, if a problem arises.

\section{CONCLUSIONS}

This review identified and classified the main smart clothing that are used in sports. From this study, evidence emerged that Europe represents the most productive continent 
with the $72 \%$ followed by Asia with $12 \%$. Smart shirts are the most commonly used garment for health monitoring parameters such as heart rate in sport activities, while other garments such as pants, glove, socks and bras have been explored. Extreme sports may be ideal scenarios for the smart garment employment, because most of them are practiced in remote and adverse environments, and they often involve acrobatic stunts. Smart clothing represents a safer solution to monitoring athletic performance both for medical and research purposes. Together with telemedicine, smart clothing can be used in adverse environments to enable data acquisition and provide critical information regarding injury prevention and training support without hampering athletic performance.

\section{REFERENCES}

1. Andreoni G, Standoli C, Perego P. Defining Requirements and Related Methods for Designing Sensorized Garments. Sensors 2016;16(6), 769. doi:10.3390/s16060769.

2. Axisa F, Dittmar A, Delhomme G. (n.d.). Smart clothes for the monitoring in real time and conditions of physiological, emotional and sensorial reactions of human. Proceedings of the 25th Annual International Conference of the IEEE Engineering in Medicine and Biology Society (IEEE Cat. No.03CH37439). doi:10.1109/iembs.2003.1280974.

3. Balmain B, Tuttle N, Bailey J, Cheng K, Duryea M, Houlihan J, Morris N, et al. Using Smart Socks to Detect Stepcount at Slow Walking Speeds in Healthy Adults. International Journal of Sports Medicine 2018; 40(02): 133-138. doi:10.1055/a-0732-5621.

4. Bryson, D. Designing smart clothing for the body. Smart Clothes and Wearable Technology 2009; 95-107. doi:10.1533/9781845695668.1.95.

5. Chan M, Estève D, Fourniols JY, Escriba C, Campo E. Smart wearable systems: Current status and future challenges. Artificial Intelligence in Medicine 2012; 56(3): 137-156. doi:10.1016/j.artmed.2012.09.003.

6. Chittenden T. Skin in the game: the use of sensing smart fabrics in tennis costume as a means of analyzing performance. Fashion and Textiles 2017; 4(1). doi:10.1186/s40691-017-0107-z.

7. Cho H, Lee JH. A Study on the Optimal Positions of ECG Electrodes in a Garment for the Design of ECG-Monitoring Clothing for Male. Journal of Medical Systems 2015; 39(9). doi:10.1007/s10916-015-0279-2.

8. Di Rienzo M, Meriggi P, Rizzo F, Castiglioni P, Lombardi C, Ferratini M, Parati G. Textile Technology for the Vital Signs Monitoring in Telemedicine and Extreme Environments. IEEE Transactions on Information Technology in Biomedicine 2010;14(3): 711-717. doi:10.1109/titb.2010.2048921.

9. Dabby N, Girouard S, Aleksov A, Lewallen E, Oster S, Fygenson R, Klein S, et al. A scalable process for manufacturing integrated, washable smart garments applied to heart rate monitoring. Proceedings of the 2017 ACM International Symposium on Wearable Computers - ISWC '17 2017. doi:10.1145/3123021.3123045.

\section{LIMITATIONS}

The Newcastle-Ottawa Scale Quality Assessment Scale (NOS) was used to evaluate the quality of the studies selected in this review. However, this method presents difficulties in evaluating the scoring since the topic is multidisciplinary. Normally a score $\geq 7$ is attributed to studies of high quality. In this review all the studies presented a score $<7$ indicating low quality. Smart clothing is a new emerging innovative technology that need much more to be tested, explored and validated to satisfy the NOS scores.

\section{CONFLICT OF INTERESTS}

The authors declare that they have no conflict of interests (32).

10. Feletti F. Research in Extreme Sports Medicine - The outdoor lab. with Human Body in Motion Congress, Université libre de Bruxelles (ULB) - Solbosch, Université libre de Bruxelles (ULB) April 2017. Doi:10.13140/RG.2.2.30397.05603

11. Gaddis, R. What is the future of fabric? These smart textiles will blow your mind, Forbes May 7, 2017.

12. GhahremaniHonarvar M, Latifi M. Overview of wearable electronics and smart textiles. The Journal of The Textile Institute 2016;108(4): 631-652. doi:10.1080/00405000.2016. 1177870 .

13. Harris JD, Quatman CE, Manring MM, Siston RA, Flanigan DC. How to write a systematic review. Am J Sports Med. November 2014;42(11):2761-8. doi: 10.1177/0363546513497567. Epub 2013 Aug 7.

14. Helmer RJN, Mestrovic MA, Farrow D, Lucas S, Spratford W. Smart Textiles: Position and Motion Sensing for Sport, Entertainment and Rehabilitation. Advances in Science and Technology 2008; 144-153. doi:10.4028/3-908158-17-6.144.

15. Joyce K. Smart textiles: transforming the practice of medicalisation and health care. Sociol Health Illn 2019; 41: 147-161. doi:10.1111/1467-9566.12871.

16. Koncar V. Smart textiles for monitoring and measurement applications, in Smart Textiles for In Situ Monitoring of Composites, The Textile Institute Book Series. Elsevier 2019; 1-151. https://doi.org/10.1016/B978-0-08-102308-2.00001-2

17. Lam Po Tang, S. Wearable sensors for sports performance. Textiles for Sportswear 2015; 169-196. doi:10.1016/b978-178242-229-7.00008-4.

18. Manshahia M, Das A, Alagirusamy R. Smart coatings for sportswear. Active Coatings for Smart Textiles 2016; 355-374. doi:10.1016/b978-0-08-100263-6.00015-0.

19. Mečnika V, Hoerr M, Krieviňš I, Schwarz A. Smart textiles for healthcare: applications and technologies 2014.

20. Meinander H. Smart and intelligent textiles and fibres. Textiles in Sport 2005. doi:10.1201/9781439823804.ch7.

21. McCann J. The garment design process for smart clothing: from fibre selection through to product launch. Smart Clothes and Wearable Technology 2009; 70-94. doi:10.1533/9781845695668.1.70. 
22. Mondal S. Phase change materials for smart textiles - An overview. Applied Thermal Eng. 2008; 28(11-12): 1536-1550. doi:10.1016/j.applthermaleng.2007.08.009

23. Pailes-Friedman R. Smart Textiles for Designers: Inventing the Future of Fabrics Paperback ; Laurence King Publishing 2016;19.

24. Perego P, Moltani A, Andreoni G. Sport monitoring with smart wearable system. Stud Health Technol Inform. 2012;177:224-8.

25. Rantanen J, Hännikäinen M. Data transfer for smart clothing: requirements and potential technologies. Wearable Electronics and Photonics 2005;198-222. doi:10.1533/9781845690441.198

26. Rossi, R. M. High-performance sportswear. High-Performance Apparel 2018; 341-356. doi:10.1016/b978-0-08100904-8.00017-1

27. Syduzzaman P, Farhanaz K, Ahmed S. Smart textiles and nano-technology: a general overview, Journal of Textile Science and Engineering 2015; 5, 181.
28. Tyler DJ. Joining of wearable electronic components. Joining Textiles 2013; 507-535. doi:10.1533/9780857093967.4.507

29. Uotila M, Mattila H, Hänninen O. Methods and models for intelligent garment design. Intelligent Textiles and Clothing 2006; 5-18. doi:10.1533/9781845691622.5

30. Van Langenhove L. Smart textiles for protection: an overview. Smart Textiles for Protection 20013; 3-33. doi:10.1533/9780857097620.1.3

31. Wood J. Revolutions in wearable technology for apparel. High-Performance Apparel 2018; 325-339. doi:10.1016/ b978-0-08-100904-8.00016-x

32. Padulo J, Oliva F, Frizziero A, Maffulli N. Muscles, Ligaments and Tendons Journal - Basic principles and recommendations in clinical and field Science Research: 2018 update. MLTJ 2018; 8(3): 305 - 307. 